\title{
Study on Library Mobile Information Services for Library Users Demand
}

\author{
Qiang Zhao ${ }^{1}$ \\ ${ }^{1}$ Xi'an International University, Xi'an, Shaan'xi, 710077 \\ 346591653@163.com
}

KEYWORDS: User Demand; Library; Mobile Information Service

\begin{abstract}
Books in the development of human society and civilization evolution documented and retained in the form of text down, library books charged with the task of saving human culture, social development process in a variety of documents and materials collection, processing and finishing, having high social value of education, libraries under development and construction of our society, have made significant progress in the construction of scientific management and service literature resources. With the globalization of information and the rapid development of digital networks, user access to information means and channels are constantly advancing with the times, it has undergone a fundamental change in the new era of development in the form of actual demand from the user library starting situation, the formation of mobile information services library innovative model to promote their sustainable development. Construction Based on this, the concept of mobile information services for users as the main starting point to explain the current situation of the development of mobile services, and user-oriented mobile information needs of library service mode onrush to explore.
\end{abstract}

\section{Introduction}

Under the new normal background China's economic development, the library should firmly grasp the opportunity for development in this era of information technology, the user needs to reform itself as the innovation and development, and constantly optimize the mobile library information service adjustment mode, build their own accord development and construction, demand for new user-oriented development system, give full play to promote the role of libraries in our society, economy, culture and other aspects of various documents, academic information for effective dissemination, in order to provide users with more high-quality service, user-oriented needs of mobile library service in line with the development trend in today's information era, under the dual drive science and technology and information technology, library information services will move towards the digital direction, and thus meet the user multi-faceted We need to realize their own leaps and bounds.

\section{The User Demand for Mobile Information Service Overview}

User demand for mobile information services from the actual needs of users, to meet different user needs at various levels, and as the starting point and foothold, in-depth field research work, analysis of specific characteristics for different users and research, through the information network technology and scientific and technical information systems design, improve and maintain this as an important basis to carry out mobile information service mode. Globalization and technological innovation in the information technology development process, the needs of library users will also 
change with the times change, a certain degree of variability in digital mobile environment with strong flexibility characteristics, timing and space dealing with the more traditional approach of the library more efficient, so the user needs for mobile information services to fully take into account the temporal and spatial characteristics of the two factors, and as the main factors users demand. In time-based user demand, in carrying out the process of implementation and mobile information service, according to customer demand-oriented customer a reasonable time schedule, the time to provide customers with a variety of types of library information services.

\section{The User Demand for Mobile Information Services Library}

Rapid socio-economic development and the continuous improvement of people's living standards, scientific and information services gradually towards the direction of diversification, and more focus on user needs and experience, and as an important part of senior development and construction, in which under the influence of trends, mobile library information service focused on the needs of users, the library service model will also be a fundamental change, to achieve a qualitative leap. Among the digital and mobile technology field of the environment, social development process of the library as a service organization, to change the traditional concept of service, user information as an important and critical part of the senior department of sustainable development, will the purpose of serving the library throughout the mobile information service always.

Library Information Service to continue to move with the times, adapt to the new trend of the times, constantly being given new meaning in the process of social development, the establishment of user needs as the center of the mobile library information service model, as a new the mode of information service, with easy access, timeliness and efficiency characteristics, and constantly improve the efficiency of the development process to obtain user information, greatly improved the level and quality of mobile library information services, thereby increasing customer satisfaction degree. According to the data shows that mobile Internet users accounted for 92.26 percent of the total user population, 18-40 years old accounted for a large proportion, we can see, to carry out mobile library information service has broad market prospects, the potential number of users very much. Process Library Mobile Information Service to consider the needs of users, preferences, will be built in close connection with the timeliness and personal characteristics and mode of development, and this advantage as the conditions of its development, and the specific needs of different customers are progressive step resource adjustment and configuration. Mobile Information Management Library staff can build a database of user information, the user retrieves the content for effective processing and analysis to meet our customers diversified and personalized information needed to make mobile information services libraries toward human culture, comprehensive and efficient direction.

\section{The Information Needs of Library Users under the Mobile Environment}

Stylized needs of library users have a relatively significant stability, ability to respond to environmental change is not strong, but the information needs of library users in mobile field of the environment has a certain plasticity, the impact of user information needs time and space by larger, and subsequently change. Temporary demand information needs of users were referred by the impact of real-time demand, user-generated library is usually affected by some kind of time or factors under the mobile environment, by logging library mobile information platform for content retrieve or query, this real-time requirements have sudden and temporary double features, user 
needs and time information between a certain linkage and association, according to the user different treatment time is divided into time savings It was killing time and killing time period of two types, for example, when the user or check real time emergency information was to save time, users or sporadic use of leisure time for information processing. Contact user information needs and may be referred to the space between the geographic demand, factors are location, infrastructure, public transport routes, space requirements for library users relative to other entertainment weaker demand, but also important information content is in demand. In addition, the way in mobile information needs of library users are also areas of environmental and information services, the system has a close relationship, the rapid development of science and technology of mobile networks have Wifi, 2G, 3G and 4G networks involving multiple service terminals, in order to meet the diverse information needs of the user.

\section{Mode Construction of Mobile Information Services}

Establish a correct concept of mobile information services library, will be the guiding ideology of people-centered scientific concept of development as its own model constructed to the needs of users as the main starting point, the formation of innovative user-oriented service concept. In the process of moving the Library Information Service built in to the actual needs of users as the fundamental principles and the starting point of the work, as a core to optimize the rational allocation of resources and efficient integration, the design of targeted mobile library information service system using methods and techniques to have a distinctive feature of human nature, we will improve the quality and efficiency of their work as an important measure of the level of service user information query. Meanwhile, the mobile library information service mode to have character, to meet the different needs of multi-user system requirements, the literature as having the characteristics of their own development characteristics of the complete system towards, accurate information on the development of the defense, for the relevant the researchers provide a more authoritative mobile information services.

Effective integration of mobile information resources, optimize the rational allocation of internal library of documents, adjust the structure of the internal management and library services, enhance the added value of mobile library information services and improve their core competitiveness, so as to realize the library across development. Literature library involves multiple parties to show off, the relevant staff to strengthen information collection and processing, to improve their ability to integrate resources, to ensure efficient convergence of the information, the information from the text, networking, and electronic information and other information aspect of a comprehensive and timely collection of integration and strengthening collaboration with other publishers, the establishment of specialized libraries square exhibition, and related website links and navigation, information resources towards the efficient and scientific the direction of development, improve the efficiency and level of library information service.

To make systematic management of mobile users of the library, on the first login, strict record the user's personal information, and other information to be recorded on the account is accurate, and to gather some information logon information, such as age. Allows the user Forgotten password from happening, you can easily access on the network. In the background of the user information registration and inclusion into the database properly saved, and from time to time to take the investigation. Secondly, the need for the user to set certain privileges to the user the type of division, and set different levels of users, appropriate to classify a certain set of privileges. Set permissions can effectively prevent hackers supply behavior. At the same time, to the user's personal browsing habits recording the background, recording the necessary user browsing way for users to provide 
personal information service reference. Finally the user advisory doubt appropriate feedback mechanisms established to facilitate user access to effective information feedback to their own needs within the available time, to avoid customer churn, etc. due to appear user feedback is not timely and emerging issues.

Mobile library information service quality is not only about the development of the library, but also about the survival of the library. In the new media age, the traditional library knowledge to enhance the level of service has been unable to strengthen the use of mobile information technology is indeed a trend. However, evaluation of the mobile library service quality and information technology needs to the needs of users shall prevail. Therefore, the library information services through mobile information technology innovation are necessary to ensure that important initiatives can effectively improve the quality of service. Therefore, the direction of the library should be fully clear modernization of information technology to conduct a comprehensive library of mobile innovation, advance with the times to promote the current library information service mode through the advantages of technology and quality of information to promote the mobile library service rising, in this process, for the needs of different user groups as the target direction for technological innovation, enabling mobile information services library technology continues to improve.

\section{Conclusion}

In summary, the rapid rise of the digital information age makes social development presents digital, network development trend, based on this, the mobile library service to meet the gradual integration of the information services in which the user needs. Science Applications digital means to realize the construction of digital library and to ensure the scientific development of digital mobile terminal. In this regard, the paper needs to ensure user-oriented mobile services building in science, the first mobile information service on the Mobile Information and Library building elaborate and develop scientific information service model architecture to real mobility needs, we hope to promote movement library Information construction services, mobile information services to ensure the development of science library.

\section{REFERENCE:}

[1] Zheng Dejun, Shen Junwei, Zhang Zhenghui. User Needs Survey and Development Proposals, Mobile Library Services [J]. Library And Information Service, 2014,07: 46-52.

[2] Li Hong. User-Oriented Digital Library Information Service Model [J]. Information Science, 2007,08: 134-136.

[3] Zou Wei. Based Mobile Library Information Service Quality Evaluation Model of Customer Satisfaction [J]. University of Libraryand Information Science, 2015,02: 74-78. 